\title{
PRINCIPIO DE INFORMALISMO
}

\section{Principle of informalism}

Héctor Mujica Acurio*

Universidad Nacional de San Antonio Abad del Cusco

\section{Resumen}

En el presente artículo el autor analiza la implicancia y alcance del principio de informalismo en el tratamiento de los procedimientos administrativos en el Perú, y concluye con la sugerencia de su aplicación general.

Palabras clave: Formalidad; interés público; debido procedimiento; subsanación.

\section{Abstract}

In this article the author analyzes the implications and scope of the principle of informality in the treatment of administrative procedures in Peru, concluding with the suggestion of general application.

Keywords: Formality; public interest; due process; correction.

\section{CUESTIONES PRELIMINARES}

\subsection{Motivación}

La motivación que me surge para escribir este artículo es la práctica constante que tenemos los ciudadanos a quienes en no pocas ocasiones se nos

* Abogado por la Universidad Nacional de San Antonio Abad del Cusco. Magister en Finanzas y Derecho Corporativo por la Universidad ESAN. Posgrado en Análisis Económico del Derecho por la Universidad de Buenos Aires. 
observa un procedimiento, un trámite que seguimos ante alguna entidad pública definida como tal en la ley y ante aquellas entidades privadas que cumplen algunos cometidos públicos, debido a que no se ha seguido rigurosamente alguna formalidad, motivo por el cual en el mejor de los casos nuestro procedimiento es retrasado o en el peor de los casos es rechazado y debemos iniciarlo nuevamente «porque no lo hicimos en la forma que debía hacerse», lo cual conlleva a la pérdida de tiempo y dinero para los ciudadanos y también para las mismas entidades, situación que considero debe revertirse.

Sin embargo, antes de entrar en materia, quiero precisar, que con las ideas que voy a plantear no pretendo que se consagre una regla de informalidad, en el sentido de que podamos seguir procedimientos administrativos de «cualquier manera», sino que simplemente no se impongan formas sin sustento normativo o que respondan a directivas internas, que suceden, por ejemplo, cada vez que hay un cambio de gestión; que las formas no prevalezcan sobre los derechos de los ciudadanos, y que por el contrario la administración pública actúe al servicio de ellos dentro del principio de legalidad, guiados por las finalidades públicas que tienen y que respondan efectivamente a una necesidad de servicio por la cual acuden los ciudadanos y no por temor a observaciones de parte del órgano de control —el cual, dicho sea de paso, también debería actuar sin privilegiar sus propios objetivos a expensas de los fines públicos y los derechos de los ciudadanos-, ya que el aparato estatal debe estar al servicio de los ciudadanos, como elemento de legitimidad y desarrollo.

\subsection{Aproximación al concepto y sus alcances}

Una primera idea de este principio proviene de su semántica, la cual nos lleva a la negación del formalismo. Ahora bien si tenemos presente que esta idea del informalismo tiene la jerarquía de principio del procedimiento administrativo, nos permite colegir que este es un claro elemento diferenciador respecto del proceso civil, en el cual se consagra el principio opuesto es decir el de formalidad'.

1 Artículo IX del Código Procesal Civil Las normas procesales contenidas en este Código son de carácter imperativo, salvo regulación permisiva en contrario.

Las formalidades previstas en este Código son imperativas. (El énfasis es propio.)

Sin embargo, el Juez adecuará su exigencia al logro de los fines del proceso. Cuando no se señale una formalidad específica para la realización de un acto procesal, éste se reputará válido cualquiera sea la empleada. 
Y es que, probablemente, una de las razones por las cuales el informalismo se erige como principio, como regla en el procedimiento administrativo, es su carácter cotidiano y democratizador, toda vez que la posibilidad de que cualquier ciudadano acuda a la administración pública está ligada a su quehacer diario, a su derecho de petición, de participación; a diferencia del proceso civil, al cual se acude sólo para resolver un conflicto de intereses o eliminar una incertidumbre jurídica, y en el cual la defensa es cautiva, y seguramente cuidará de observar las formas procesales para resguardar los derechos de la parte a quien patrocina.

Una segunda idea que nos aproxima a este principio es que está consagrada como una regla de interpretación, orientada a la admisión de las pretensiones, lo cual refleja el contenido del principio pro actione de raigambre constitucional, así como de tutela de derechos e intereses subjetivos, los que claro está no tendrían que verse afectados por la inobservancia de formas.

Las ideas anteriores van unidas a la posibilidad de subsanar la exigencia de aspectos formales, aspecto que es completamente viable en el procedimiento administrativo, situación que por el contrario es muy limitada en el proceso civil.

En efecto, recordemos que el procedimiento administrativo es la serie, secuencia o sucesión de actos que, dirigida a la satisfacción directa e inmediata del bien común o interés público, constituye el elemento ordenador, regulador y sistematizador del desenvolvimiento de la función administrativa del Estado?

Así, el sometimiento de la acción administrativa a un cauce formal se justifica como garantía desde dos perspectivas: como garantía del interés público y de los derechos de los particulares. Se trata, entonces, de admitir un conjunto de formas jurídicamente reguladas que se cumplen por y ante los órganos que ejercen aquella función, con el objeto de preparar la emisión de actos administrativos. Por ello, es un instrumento de control, tanto de la legitimidad como del acierto de las decisiones en relación al interés público³.

De esta manera, el procedimiento administrativo viene a ser un instrumento para la protección del interés en general, en equilibrio de los derechos de los particulares que adquieren el rol de administrados cada vez que

2 COMADIRA, Julio. Procedimiento administrativo y denuncia de ilegitimidad. Buenos Aires: Abeledo-Perrot, 1996; p. 11.

3 IVANEGA, Miriam. El principio del informalismo administrativo. En: Revista Derecho PUCP n. ${ }^{\circ}$ 67, Lima: Fondo PUCP, 2011 ; p. 156. 
acuden ante la Administración Pública, y más modernamente como usuarios, por ello una adecuada comprensión del principio resulta necesaria, más aun si tenemos presente que el procedimiento debe reflejar el orden jurídico de la actividad concreta y permanente de función administrativa.

\subsection{Delimitación de los principios del procedimiento administrativo}

Expresadas estas ideas iniciales, cabe ahora abordar en primer lugar la significación del principio en general y para luego abordar la significación de los principios en el procedimiento administrativo.

Respecto de la significación general de los principios, Gordillo señala que

[e]l principio determina en forma integral cuál ha de ser la orientación del acto de creación o aplicación del derecho. Un intérprete o ejecutor del derecho no puede ser un mero lector del texto de cada norma, sino que debe fundamentalmente buscar la interpretación que la hace justa en el caso: allí es donde son de aplicación los principios jurídicos por ser principios son la base de una sociedad libre y democrática, son los elementos fundamentales y necesarios de la sociedad y de todos los actos de sus componentes ${ }^{4}$.

Ahora bien si trasladamos el significado de los principios al procedimiento administrativo, podremos notar, citando a Morón, que no son otra cosa que los elementos que el legislador ha considerado básicos para encausar, controlar y limitar la actuación de la Administración y de los administrados en todo procedimiento, elementos que controlan la liberalidad o discrecionalidad de la Administración en la interpretación de las normas existentes, así como en la integración jurídica para resolver aquello no regulado, y como elemento para desarrollar las normas administrativas complementarias $^{5}$. Elementos que han sido positivizados en el numeral 2 del artículo IV de la Ley N. ${ }^{\circ} 27444$, y que dotan de funcionalidad a los principios del procedimiento administrativo.

Ahora bien, dentro de la distinción de los principios, cabe ubicar al Informalismo como un Principio institucional, ya que pertenece a la naturaleza inherente al ámbito administrativo por explicitar el contenido de los actos y procedimientos administrativos. Sin embargo, para apreciar su alcance, la doctrina aconseja diferenciar entre aquellos principios de la actividad

4 IVANEGA, Miriam. Ob. cit. p. 164.

5 MORÓN, Juan. Comentarios a la Ley del Procedimiento Administrativo General. Lima: Gaceta Jurídica, 2005; p. 58. 
administrativa, de los principios del procedimiento administrativo strictu sensu. Por los primeros, tenemos aquellos que constituyen pautas medulares que proyectan su acción sobre todas las actuaciones públicas, y que son los principios de impulso de oficio, imparcialidad, uniformidad y predictibilidad. A su vez, los principios del procedimiento strictu sensu son los de informalismo, presunción de veracidad, celeridad, eficacia, verdad material, simplicidad y privilegio de controles posteriores ${ }^{6}$.

Finalmente, sobre la significación de los principios cabe hacer énfasis en que la vinculación de las autoridades administrativas con estos principios es directa, sin necesidad de regulación adicional, reglamentación, orden superior, o cualquier acción jurídica intermedia o particularización al caso que se encuentra en trámite. Constituyen verdaderos deberes ${ }^{7}$, por ser operativos directamente, para los procedimientos comunes y especiales ${ }^{8}$.

\subsubsection{Clasificación y ubicación}

Resulta útil no sólo para efectos académicos, sino también para lograr un adecuado entendimiento e interpretación, abordar este tema y es que, como sostiene Gordillo, los grandes principios del procedimiento administrativo son de carácter constitucional, de justicia natural y de derecho supranacional, dado que garantizan la defensa de los derechos civiles y humanos en general del individuo y de las asociaciones en el procedimiento singular, como también la indispensable participación de la sociedad y la defensa de los derechos de incidencia colectiva en la previa elaboración y debate de las normas generales y los grandes proyectos que afectan a la sociedad, al medio ambiente, a las grandes contrataciones, licencias, concesiones, etcétera. A ello se agrega el principio del informalismo a favor del administrado tanto en su actuación individual como en la colectiva9.

En este afán de lograr un adecuado entendimiento, acudiremos al ensayo de clasificación - lo cual a su vez nos va permitir desentrañar el origenque hace López ${ }^{10}$, quien aborda el tema desde la siguiente perspectiva:

\footnotetext{
6 Ibíd.

7 Artículo 75 de la Ley de Procedimiento Administrativo General

Son deberes de las autoridades respecto del procedimiento administrativo y de sus partícipes, los siguientes: (...)

2. Desempeñar sus funciones siguiendo los principios del procedimiento administrativo previstos en el Título Preliminar de esta Ley.

8 MORÓN, Juan. Ob. cit. p. 59.

9 IVANEGA, Miriam. Ob. cit. p. 162.

10 LÓPEZ, Francisco. Los principios generales de procedimiento administrativo. En: Revista de Administración Pública n. ${ }^{\circ} 129$, setiembre-diciembre 1992, pp. 52-57.
} 


\subsubsection{Principios del procedimiento con clara conexión en principios positivizados en la Constitución}

Nos referimos a aquellos principios del procedimiento que son traducción de principios constitucionales, o dicho de otro modo, que constituyen versiones de esos principios constitucionalizados operando en el ámbito procedimental administrativo, bajo la veste ${ }^{11}$ de principios adecuados a la naturaleza de la materia. Esos principios de procedimientos son, a su vez, susceptibles de seguir escindiéndose o particularizándose en otros principios aún menos abstractos o identificarse ya directamente; son preceptos positivos a través de los cuales materializan su operatividad y resultan claramente reconocibles. Pueden establecerse tres principios constitucionales en torno a los cuales se arraciman los diversos principios del procedimiento: 1) Principios de no indefensión y de presunción de inocencia; 2) principio de la tutela del interés público; 3) principio de eficacia.

Dentro de la clasificación que hace López, se resaltarán los que tienen mayor incidencia en la formación del principio de informalismo, según diversos pronunciamientos del Tribunal Constitucional español. Así pues cabe señalar dentro de los primeros a los siguientes:

a) Principio «in dubio pro actione» o regla general de la interpretación más favorable al ejercicio de las acciones, que se traduce en la necesidad de una interpretación flexible de los requisitos de legitimación; viabilidad de las pretensiones en caso de dudas sobre cómputo de plazos; resolución "pro administrado» de las dudas sobre la validez de la recepción de escritos en registros administrativos; presunción de la válida representación del interesado; regla de la no automaticidad de la caducidad por inactividad imputable al administrado y necesidad de resolución expresa.

b) Principio de subsanabilidad de los actos de los interesados: subsanación de los defectos de presentación de escritos y documentos. El error en la calificación de un recurso no impide su tramitación correcta, entre otras.

Se omitirá el desarrollo del principio de la tutela del interés público, porque este más bien inspira a otros principios, como el de impulso de oficio, mas no al principio que nos ocupa en este trabajo.

11 Bajo este término refiere al vestido o vestimenta de los procedimientos administrativos que traducen principios constitucionales. 
Finalmente en cuanto al principio de eficacia - de jerarquía constitucional en España ${ }^{12}$ - puede diversificarse, materializándose, en lo que respecta a este trabajo en el siguiente principio:

a. Principio antiformalista, pues «el exceso de formalismo es la depravación de la norma como garantía», principio que puede desdoblarse en los de celeridad y de eficacia strictu sensu. Al respecto, cita la sentencia del Tribunal Supremo Español de 6 de julio de 1988, que señala:

El Derecho Administrativo, en principio, se ha decidido por antiformalismo ponderado que, sin merma ni quiebra de la legalidad, permita el desarrollo de la situación administrativa conforme a normas y principios de celeridad y eficacia —art. 29 de la LPA y 103.1 de la Constituciónhasta el punto de que el vicio de forma o de procedimiento (descrito en los artí́culos 48 y 49 de la LPA) no se le reconoce tan siquiera virtud invalidante de segundo grado, anulabilidad, más que en aquellos casos excepcionales en que el acto carezca de los requisitos indispensables para alcanzar su fin, se dicte fuera del plazo previsto, cuando éste tenga un valor esencial, o se produzca una situación de indefensión... ${ }^{13}$

De la definición legal contenida en el numeral 1.6, del artículo IV del Título Preliminar de la Ley 27444, se aprecia que concretiza para el procedimiento administrativo principios de raigambre constitucional, como el de in dubio pro actione y que ya ha merecido un pronunciamiento favorable del Tribunal Constitucional peruano en la Sentencia N. ${ }^{\circ}$ 3908-2010-AA/ TC, así pues es de destacar, lo señalado en su Fundamento 5:

En el presente caso no existe justificación alguna para que la administración se niegue a recepcionar las solicitudes o recursos presentados por la demandante, al margen de requisitos formales como denominación, numeración, sumillas, hojas de información, etc. aprobados por la normativa interna de la SUNAT...

Podemos notar también que los principios referidos por López, relativos a la subsanabilidad y antiformalista, están claramente contenidos en la definición del principio de informalismo por el que ha optado el legislador nacional en la Ley 27444.

12 Artículo 103 de la Constitución Política de España

1. La administración pública sirve con objetividad los intereses generales y actúa de acuerdo con los principios de eficacia, jerarquía, descentralización, desconcentración y coordinación, con sometimiento pleno a la ley y al Derecho. (El énfasis es propio.)

13 LÓPEZ, Francisco. Ob. cit. p. 57. 


\section{TRATAMIENTO NORMATIVO EN EL PERÚ}

\subsection{Definición legal}

La Ley N. ${ }^{\circ}$ 27444, Ley del Procedimiento Administrativo General, define al principio de informalismo del siguiente modo:

«1.6. Principio de informalismo.- Las normas de procedimiento deben ser interpretadas en forma favorable a la admisión y decisión final de las pretensiones de los administrados, de modo que sus derechos e intereses no sean afectados por la exigencia de aspectos formales que puedan ser subsanados dentro del procedimiento, siempre que dicha excusa no afecte derechos de terceros o el interés público».

Como podemos apreciar esta definición es una especie de síntesis y de reflejo de su ubicación que hemos desarrollado.

\subsection{Consolidación del concepto por la doctrina}

Sobre el particular, considero pertinente citar a lvanega, quien señala que el principio del informalismo a favor del administrado es uno de los aspectos fundamentales del procedimiento. Consiste en la dispensa a los administrados de cumplir con las formas no esenciales, es decir, aquellas que no están exigidas por el orden público administrativo. Su aplicación impide que el particular pierda un derecho por el incumplimiento de un deber formal, con lo que obliga a la administración a optar por la solución más favorable para aquel. En definitiva, se propugna un equilibrio entre la acción administrativa que no puede ser entorpecida y el derecho de los administrados a no encontrarse sometidos a rigorismos que los periudiquen, porque sería inconstitucional negar una solución al particular por causas meramente formales ${ }^{14}$.

También denominado formalismo moderado y debilitamiento de la preclusión, consiste básicamente en la dispensa a los administrados de cumplir con las formas no esenciales, es decir aquellas que no están ligadas o exigidas por el orden público administrativo.

Como había comentado en el capítulo relativo a su ubicación y clasificación, el principio del informalismo responde a la regla jurídica in dubio pro actione, y se vincula estrechamente con la tutela administrativa efectiva, por eso se admite la aplicación del principio aquí comentado al cómputo de plazos, a la legitimación, a la decisión de si el acto es definitivo o de mero trámite, a la calificación de los recursos, entre otros.

14 IVANEGA, Miriam. Ob. cit. p. 155. 
En este punto, cabe comentar que los plazos son obligatorios tanto para la administración como para los administrados; sin embargo, pueden presentarse casos en los cuales su cómputo pueda dar lugar a duda, como por ejemplo, cuando una entidad no atiende con normalidad debido a una festividad interna, situación que se ve atendida en el artículo $134.2^{15}$ de la Ley N. ${ }^{\circ} 27444$.

Este principio no puede ser invocado por la administración para eludir sus facultades regladas, pues es ilegítimo que aquella se ampare en la dispensa de formas para dejar de cumplir con las exigencias que el orden jurídico le impone a toda su actuación, o para dejar de cumplir con las reglas del procedimiento. A nivel nacional, Morón precisa que el administrado sólo puede invocar el principio para legitimar la inobservancia por su parte de requisitos formales (recaudos, firmas, sellos, anexos); pero nunca puede ser entendido como una regla a favor de la Administración para omitir el cumplimiento de las exigencias legales de ninguna índole o generarse espacios de discrecionalidad en sus decisiones.

Su aplicación impide que el particular pierda un derecho por el incumplimiento de un deber formal, debiendo la administración optar por la solución más favorable para aquel en dicho sentido.

En definitiva, como ya he referido este principio propugna un equilibrio entre la acción administrativa - que no puede ser entorpecida- y el derecho de los administrados a no encontrarse sometidos a rigorismos que los periudiquen. Ello porque sería inconstitucional negar una solución al particular por causas meramente formales.

La citada jurista argentina agrega que cabe reconocer la dificultad de determinar qué formas son esenciales y cuáles no. Más allá del casuismo que ello implica, es posible considerar como formalidades no esenciales a las irregularidades intrascendentes que no provocan vicio alguno, defectos formales vinculados a las nulidades relativas -entiéndase a los actos que son pasibles de conservación según el artículo 14 de la Ley N. ${ }^{\circ} 27444$-, o aquellos que no vulneran el orden público ni comportan una nulidad absoluta.

Lo «no esencial» es comprensivo de las meras o simples inobservancias administrativas que pueden ser subsanadas, sin agravio a terceros, al interés público o a la esencialidad de la juridicidad. Por el contrario, las

15134.2 Cuando el último día del plazo o la fecha determinada es inhábil o por cualquier otra circunstancia la atención al público ese día no funcione durante el horario normal, son entendidos prorrogados al primer día hábil siguiente. 
formas esenciales se vinculan al orden público, a los requisitos fundamentales del acto administrativo, a los derechos humanos y al debido proceso administrativo.

\subsection{Efectos y aplicación del principio de informalismo}

En nuestra doctrina nacional Morón ${ }^{16}$ señala sobre este principio que «el efecto esencial del principio es dar la responsabilidad a las autoridades instructoras de morigerar o debilitar el rigorismo de cualquier exigencia adjetiva que no afecten al interés público, para favorecer al administrado en el avance del procedimiento».

La admisión de los medios probatorios presentados aun cuando está vencido el plazo formal si aún no se ha resuelto el procedimiento. Por nuestra parte, queremos agregar el hecho de que la principal aplicación de este principio está en la interpretación favorable que debe hacerse de las normas del procedimiento, de manera similar a lo que ocurre por ejemplo en materia penal o laboral, o una materia más relacionada como es el derecho del consumidor ${ }^{17}$.

Sobre esta última idea, Ivanega señala que el principio determina en forma integral cuál ha de ser la orientación del acto de creación o aplicación del derecho. Un intérprete o ejecutor del derecho no puede ser un mero lector del texto de cada norma, sino que debe, fundamentalmente, buscar la interpretación que la hace justa en el caso: allí es donde son de aplicación los principios jurídicos por ser principios son la base de una sociedad libre y democrática, son los elementos fundamentales y necesarios de la sociedad y de todos los actos de sus componentes.

Lo que debe evitarse, entonces, son aquellas formas que impidan desentrañar el verdadero meollo del caso, la verdad y, en última instancia, hacer justicia. En las presentaciones del administrado deben atenderse su contenido y finalidad, dejando de lado el modo en que fueron tituladas ${ }^{18}$.

Como podemos apreciar, este principio se consagra como muy propio del procedimiento administrativo y del derecho administrativo en general, diferenciándose sustancialmente del proceso civil, precisamente porque busca ese equilibrio entre los intereses generales y los particulares.

16 MORÓN, Juan. Ob. cit. pp. 74 y 75.

17 Código de Protección y Defensa del Consumidor

Artículo Il.- Finalidad

(...) En el régimen de economía social de mercado establecido por la Constitución, la protección se interpreta en el sentido más favorable al consumidor, de acuerdo a lo establecido en el presente Código. (El énfasis es propio).

18 IVANEGA, Miriam. Ob. cit. p. 174. 


\subsection{Límites al principio}

Comentando este principio Morón hace una interesante precisión al señalar que ello no puede conducirnos a desnaturalizar el procedimiento y desconocer reglas adjetivas establecidas a favor de los terceros o del interés público.

La clave para diferenciar las formalidades en las que aplicará este principio debe verse casuísticamente, pero siempre de la mano con el principio de conducta procesal.

Es importante destacar también que la aplicación de este principio no nos puede llevar a concebir un procedimiento sin formas, puesto que ello sería imposible cuando sabemos que el principio de legalidad es uno de los pilares de la actividad administrativa.

Además considero pertinente agregar que este principio se relativiza en los procedimientos trilaterales, por cuanto en este corresponde a las partes ser más precisas en sus pretensiones y en el aporte de sus medios probatorios, pues en este la administración debe actuar con imparcialidad, siendo difícil que pueda aplicar en la misma medida el informalismo a favor de dos administrados con intereses contrapuestos.

\subsection{Breves notas sobre las relaciones con otros principios del procedimiento administrativo}

Siguiendo la clasificación de los principios que hace Morón, citada líneas arriba, se hará una síntesis que relaciona el principio de informalismo con los demás principios contenidos en la Ley n. ${ }^{\circ} 27444$ :

Cuadro. Principios regulados en la Ley del Procedimiento Administrativo General, Ley n. 27444.

\begin{tabular}{l|l}
\multicolumn{1}{c}{ Otros principios } & \multicolumn{1}{c}{ Relaciones } \\
Legalidad & $\begin{array}{l}\text { Rige toda la actividad administrativa. Se complementa en la } \\
\text { interpretación de las reglas de procedimiento, debe prevalecer } \\
\text { la más favorable al administrado. }\end{array}$ \\
\hline Contenido en el favorecimiento de la admisión de las preten- \\
siones de los administrados y que se refleja por ejemplo en la \\
no preclusividad para aportar pruebas (subsanando los defec- \\
tos que esta podría tener), argumentar, limitando la aplicación \\
del Derecho Procesal Civil a un análisis de compatibilidad.
\end{tabular}

Continúa... 


\begin{tabular}{|c|c|}
\hline $\begin{array}{l}\text { Otros } \\
\text { principios }\end{array}$ & Relaciones \\
\hline $\begin{array}{l}\text { Impulso de } \\
\text { oficio }\end{array}$ & $\begin{array}{l}\text { Hay relación de complementariedad, ya que su aplicación dis- } \\
\text { pensa al administrado de las formas no esenciales, debido a que, } \\
\text { para llegar a una decisión final, la administración debe impulsar } \\
\text { de oficio el procedimiento, sin que ello implique que la administra- } \\
\text { ción invoque el informalismo para su propia actuación. }\end{array}$ \\
\hline Razonabilidad & $\begin{array}{l}\text { Está dirigido a las obligaciones, infracciones, sanciones y res- } \\
\text { tricciones, mientras el informalismo está orientado a la tutela de } \\
\text { derechos e intereses. }\end{array}$ \\
\hline Imparcialidad & $\begin{array}{l}\text { Complementa, en la medida que de haber dos o más admi- } \\
\text { nistrados en un procedimiento, a ambos asiste el informalismo } \\
\text { por igual, aunque podría haber matices en los procedimientos } \\
\text { trilaterales en los que la administración actúa como parte (Ej. } \\
\text { Contrataciones del Estado). }\end{array}$ \\
\hline $\begin{array}{l}\text { Presunción de } \\
\text { veracidad }\end{array}$ & $\begin{array}{l}\text { También hay relación de complementariedad, en este caso orien- } \\
\text { tado a los medios probatorios y la no exigencia de formalidades } \\
\text { respecto de los mismos. }\end{array}$ \\
\hline $\begin{array}{l}\text { Conducta } \\
\text { procedimental }\end{array}$ & $\begin{array}{l}\text { También hay relación de complementariedad. Sobre todo cuando } \\
\text { prohíbe interpretación contra la buena fe. }\end{array}$ \\
\hline Celeridad & $\begin{array}{l}\text { Lo complementa en la medida que también evita actuaciones } \\
\text { que sean formalistas. }\end{array}$ \\
\hline Eficacia & $\begin{array}{l}\text { De complementariedad, evidencia el sentido finalista del pro- } \\
\text { cedimiento administrativo, prevaleciendo sobre formalismos no } \\
\text { esenciales, que atenten contra garantías o causen indefensión. }\end{array}$ \\
\hline Verdad material & $\begin{array}{l}\text { Guarda correlato con el sentido de tutela del interés general y } \\
\text { también de equilibrio entre la administración y los administrados. } \\
\text { A su vez lo hace diferente del proceso civil; las formalidades que } \\
\text { se puedan imponer en aplicación de este principio deben ser } \\
\text { moderadas. }\end{array}$ \\
\hline Participación & $\begin{array}{l}\text { De complemento y también de limitación en supuestos excep- } \\
\text { cionales. }\end{array}$ \\
\hline Simplicidad & $\begin{array}{l}\text { También hay una clara relación de complementariedad por su } \\
\text { propia definición. }\end{array}$ \\
\hline Uniformidad & $\begin{array}{l}\text { Hay complementariedad en vista de que ambos buscan brindar } \\
\text { tutela al administrado. }\end{array}$ \\
\hline Predictibilidad & $\begin{array}{l}\text { De complementariedad y de cuidado sobre el posible sentido } \\
\text { final a las peticiones del administrado. }\end{array}$ \\
\hline $\begin{array}{l}\text { Privilegio de } \\
\text { controles } \\
\text { posteriores }\end{array}$ & $\begin{array}{l}\text { De resguardo del interés público, a efectos de que no haya un } \\
\text { uso indebido del informalismo por parte de los administrados. }\end{array}$ \\
\hline
\end{tabular}

Elaboración propia.

84 Cuadernos Jurídicos lus et Tribunalis año 1, n. ${ }^{\circ}$ 1, enero-diciembre 2015 


\section{CONCLUSIONES}

Siguiendo a lvanega, el procedimiento administrativo no puede constituir un camino de exigencias que obstaculicen el ejercicio de los derechos por parte de los administrados. Las formas a su vez conforman la juridicidad de la actuación administrativa, coadyuvan a la transparencia y permiten el control de la actuación administrativa. Por ello, el formalismo moderado no puede ser sinónimo de caos procedimental, sino de equilibrio entre el ejercicio de una función administrativa transparente y el derecho de defensa del particular ${ }^{19}$.

Por mi parte, considero de suma utilidad entender y difundir los alcances de este principio, así como su compatibilidad con los otros principios del procedimiento administrativo, para que los administrados puedan hacer una aplicación adecuada del mismo y para que la administración la admita en la gran mayoría de los procedimientos que atiende, pues en la práctica y bajo la excusa de salvar eventuales responsabilidades no convierta la formalidad en una regla para los administrados.

19 IVANEGA, Miriam. Ob. cit. p. 175. 